\title{
VUmc
}

\section{DIAGNOSIS AND TREATMENT OF A SYMPTOMATIC \\ CEREBROSPINAL FLUID - CUTANEOUS FISTULA FOLLOWING \\ TUNNELLED SPINAL CATHETER REMOVAL: A CASE REPORT}

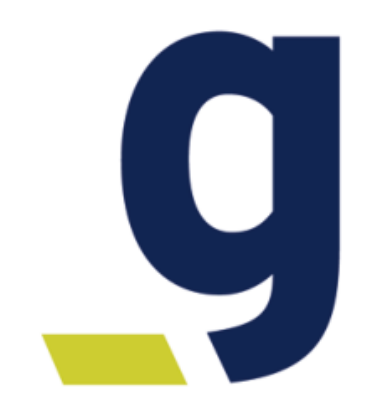

Diana A. Papazova ${ }^{1,2}$, Marjolein van der Horst ${ }^{2}$

d.papazova@vumc.nl

${ }^{1}$ Dept. Anesthesiology, VUmc, Amsterdam, the Netherlands

${ }^{2}$ Dept. Anesthesiology, Westfriesgasthuis, Hoorn, the Netherlands

\section{Background}

Cerebrospinal fluid (CSF)-cutaneous fistulas are a rare complication of neuraxial anaesthesia and analgesia techniques.

\section{Our patient}

- A 49-years-old female patient

- Diagnosed with anal carcinoma (T3N2M0)

- Received a tunnelled spinal catheter for administration of local anaesthetic for chronic pain treatment

- Three days after removal of the catheter she presented to our clinic with severe postural headache

\section{Physical examination}

Clear fluid leak from the exit site of the spinal catheter

\section{Laboratory}

Fluid was positive for beta-2-transferrin

\section{MRI-scan of patient's lumbar region}

Approximately $20 \mathrm{~cm}$ long CSF-cutaneous fistula (Fig. 1, Fig. 2)

\section{Treatment}

A deep cutaneous stitch close to the exit site of the fistula was placed, but this failed to stop the CSF leak. As conservative measures did not improve the patient's symptoms, an epidural blood patch was performed two weeks later. The postural headache diminished and disappeared two months afterwards.

\section{Discussion}

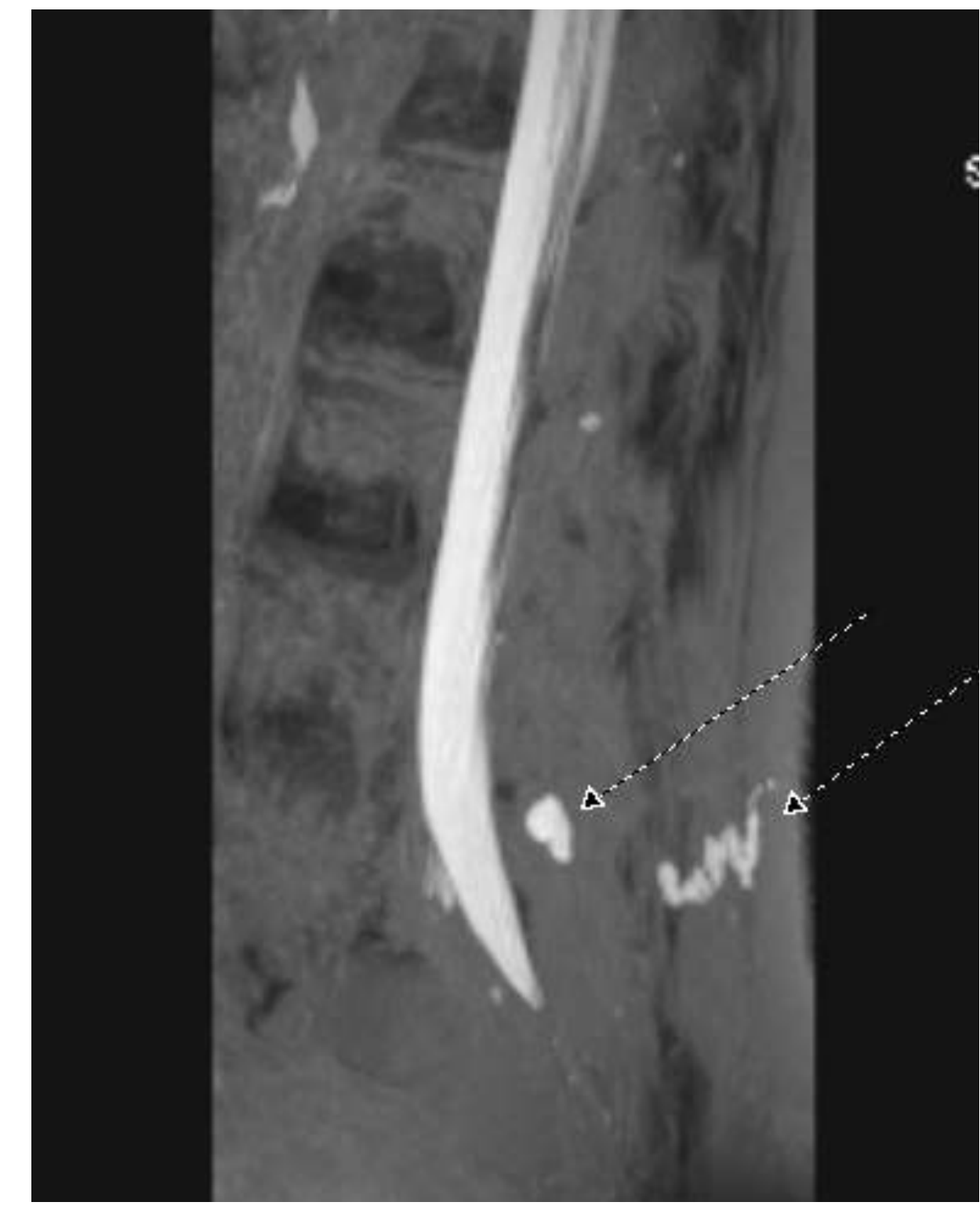

Fig. 2.Maximum intensity projection reconstruction of the CSF fistula: sagittal view

CSF-cutaneous fistulas need to be diagnosed as early as possible to avoid further complications and patient discomfort. In the presented case, treatment of this CSFcutaneous fistula was challenging due to its extensive trajectory and long-term use of spinal catheter. 